\title{
Automatic Railway Barrier System, Railway Tracking and Collision Avoidance using IOT
}

\author{
Ishan Jain \\ Department of Computer Science \\ VIT University
}

\author{
Shubham Malik \\ Department of Computer Science \\ VIT University
}

\author{
Soumya Agrawal \\ Department of Computer Science \\ UIT RGPV
}

\begin{abstract}
IOT can be used to improve various aspects of the railway system. Automation of railways can transform the current legacy systems and help decrease the railway related accidents significantly. This research paper proposes a system where sets of infrared sensors are used to track the position of the train and its direction. This information is used to close/open the railway barrier automatically via a motor connected to a microcontroller unit. It is also used to warn the driver about a possible collision with a train coming from the opposite direction via an SMS sent from the GSM module attached to the microcontroller. The position of the train is sent to a webpage via the GSM module for tracking.
\end{abstract}

\section{General Terms}

Railway barrier, safety, tracking

\section{Keywords}

Microcontroller, IOT, GSM, train collision avoidance, automatic, SMS, webpage

\section{INTRODUCTION}

In India, railways is one of the most commonly used mode of transport. On an average, over 23 million passengers were travelling in trains on any given day in 2012-13 in India. The figure indicates the importance of Railways in Indian Transport system.

Even though the system has been developing, railway accidents are a common occurrence which is a risk to the safety of passengers. As per the review of train accidents between 2009 and 2015, the data indicates that most of the railroad accidents occurred because of level crossing and derailments [1]. Therefore more efforts are necessary for improving safety of passengers and avoiding train accidents.

From Figure 1, it can be deduced that most of the accidents happen due to level crossings and derailment. Majority of these are caused due to failure of staff or others. So, it is fair to imply that avoiding human failure can reduce the number of train accidents by a large number.

With the proposed system, the number of level crossing accidents and accidents due to human failure can be reduced significantly. The open source IOT environments and cheap microcontrollers along with the internet boom enable the railway industry to employ such automated systems which reduce the calamities caused by human failure and concentrate on providing a better experience for the travelers.

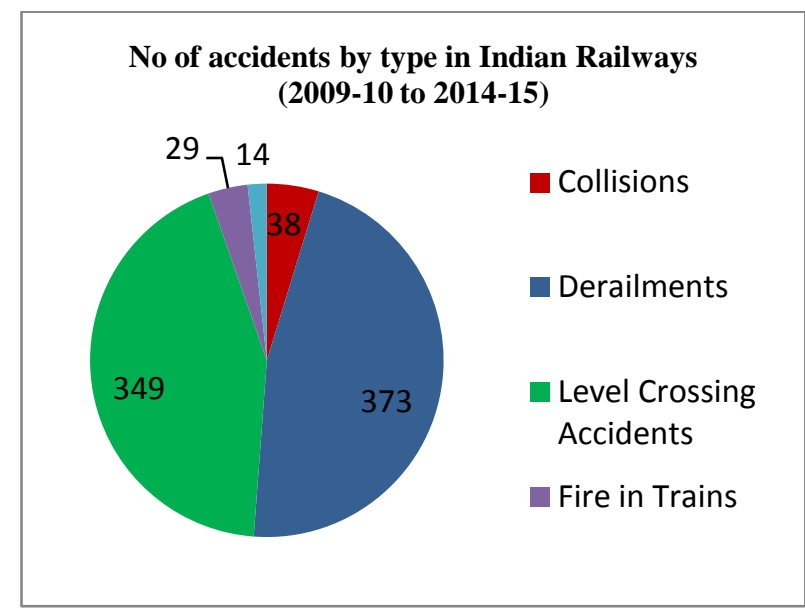

Fig. 1: Number of accidents by type in Indian Railways

\section{LITERATURE REVIEW}

K. Ajith Theja et. al. [2] focused on preventing skilled workers to operate the railway crossing and established a model to open and close railway gate automatically using Wireless Sensor network (WSN) and thus avoiding accidents caused by human errors.

Any M. Kottalil et. al. [3] proposed a tested circuit to control the opening and closing of railway gate precisely using ATMEGA 16 in order to reduce the problem of longer wait time for road passengers while waiting for passage of train.

In [4], the authors proposed a model which provides the means for real time inspection and automatic gate control using IR sensors which lessens the manual interference to avoid accidents occurring due to human negligence. Our paper also proposes this as a solution and adds more safety features with the inclusion of IOT.

Sheikh Shanawaz Mostafa et. al. [5] proposed a method for avoiding collision by using radio links in order to transfer identification, information of approaching and outgoing trains faster to avoid accidents at railway crossing.

In [6], authors did a comparison of Level crossings used across the world and aimed to embed railway crossing with automated platform bridges in order to provide automatic level crossing and reducing the wait time which wastes due to opening and closing of gate irrespective of train arrival

In "Improving Railway Safety with Obstacle Detection and Tracking System using GPS-GSM Model" [8] the authors proposed a solution encompassing GSM and GPS technologies to provide train tracking and pin pointing location of obstacles using GPS. 
D. Karthiga Devi et. al.[9] implemented an autonomous system that uses image processing techniques to identify obstacle movement along the tracks and thus focusing on preventing accidents caused due to obstacle collision.

\section{PROPOSED SYSTEM}

The proposed system is a combination of three sub systems namely, Sensor subsystem, Control subsystem and Actuator/Notification subsystem respectively. Figure 2 shows the high level system design divided into the respective subsystems.

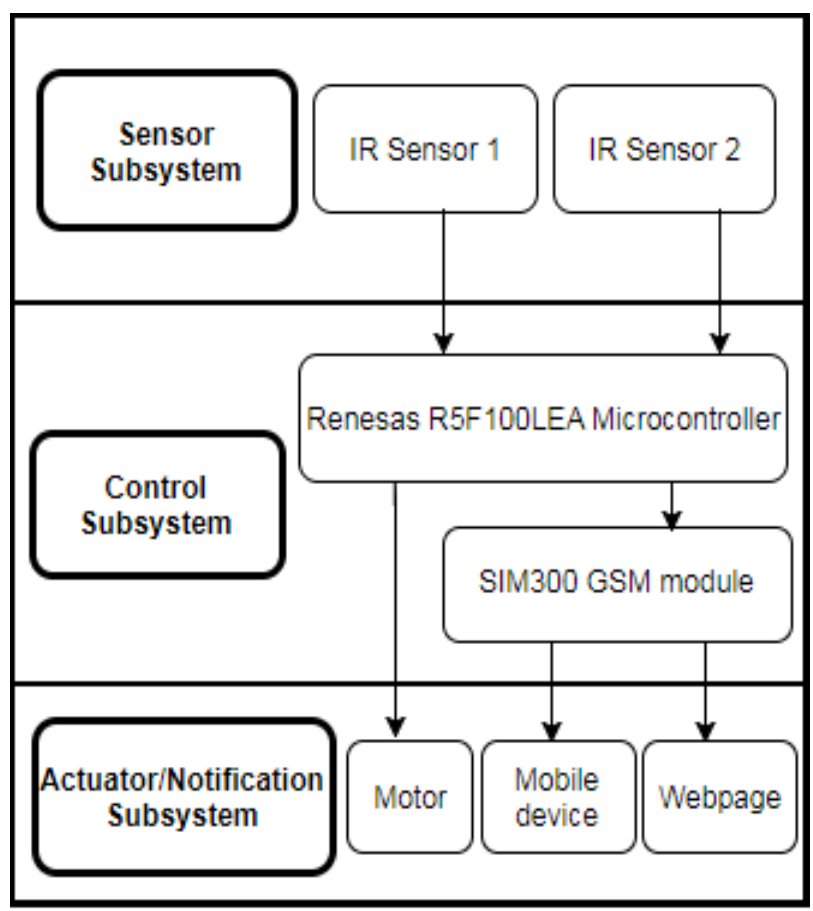

Fig. 2: High Level System Design

\subsection{Sensor Subsystem}

The sensor subsystem comprises of sets of infrared sensors that are connected to the Renesas microcontroller board. The transmitter and receiver of the IR sensor are fixed on opposite sides of the track. For sensing the crossing train two pairs of IR sensors are used instead of one to discern the direction in which the train is travelling. When both the IR sensors do not receive the infrared signals at some point in time, it is assumed that a train is crossing that point. Each tracking point has two pairs of IR sensors. Based on which sensor detects the train first, the direction in which the train is moving is concluded. Figure 3 shows the positioning of two pairs of infrared sensor ' $x$ ' and ' $y$ ' at location ' $P$ '.

If $e_{i}\left(t_{i}\right)$ is the event of detection for sensor $i$ for time $t_{i}$ and $(\mathrm{x}, \mathrm{y})$ is a pair of IR sensors at a tracking location then,

if $\left(\mathrm{e}_{\mathrm{x}}\left(\mathrm{t}_{1}\right) \& \& \mathrm{e}_{\mathrm{y}}\left(\mathrm{t}_{2}\right)\right)\{$

train_location $=\mathrm{P}$

if $\left(t_{1}>t_{2}\right)$ then train_direction $=A B$

if $\left(t_{2}>t_{1}\right)$ then train_direction $\left.=B A\right\}$

Where, $\mathrm{AB}$ means the train moves from $\mathrm{A}$ to $\mathrm{B}, \mathrm{P}$ is the location w.r.t. sensors $(\mathrm{x}, \mathrm{y})$.

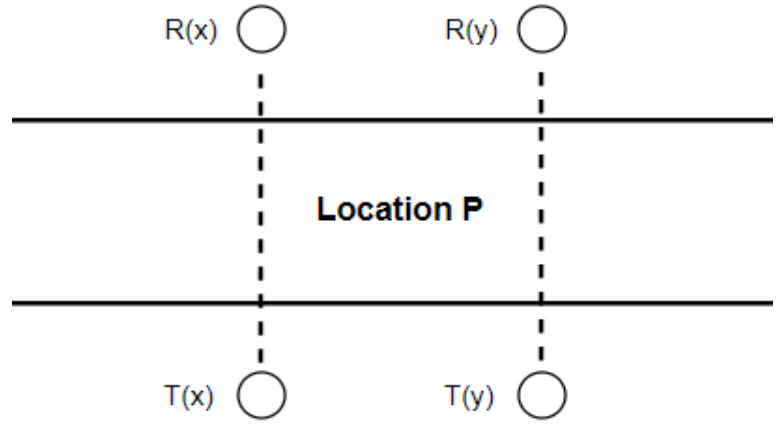

Fig. 3: IR sensors at position $P$

\subsection{Control Subsystem}

The control subsystem is the logical entity which consists of the Renesas R5F100LEA microcontroller which connects the IR sensors to the motor driver for barrier and the SIM300 GSM module. It contains the programmed logic for detecting the train and accordingly changes the barrier state, sends an SMS to the driver and station master in case of an emergency and updates the PHP webpage which shows the current location of train.

Railway Tracking: If any pair of sensor detects the train, update the specific sensor's location on the PHP webpage.

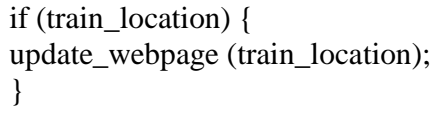

Collision Avoidance: If two trains are coming from opposite directions, a warning SMS is sent to the driver and station master about the possible collision. This case arises when two pairs of sensor in proximity detect trains to be moving in opposite direction.

\section{if $(\mathrm{AB} \& \& \mathrm{BA})\{$ send_warning_SMS(); \}}

Automatic Railway Barrier System: If a train is detected at the sensors near the railway barrier, then open/close the barrier and send an SMS to the driver and station master informing about the success or failure of opening/closing of the level crossing barrier.

if $\left(\mathrm{e}_{\mathrm{x}}\left(\mathrm{t}_{1}\right) \& \& \mathrm{e}_{\mathrm{y}}\left(\mathrm{t}_{2}\right)\right) \& \&(\mathrm{x}, \mathrm{y}) \in \mathrm{P}\{$

barrier_toggle();

send_update_SMS();

\}

Where, $\mathrm{P}$ is the set of sensors near the railway barriers.

\subsection{Actuator/Notification Subsystem:}

This subsystem consists of an Octal Peripheral Device Array ULN2803 which connects to the motor which controls the crossing barrier, a mobile device which receives alert messages in case of a possible collision and a PHP webpage that displays the current position of the train according to the sensors. The motor is connected to the microcontroller and messages and webpage updates are given using the GSM module in the control section. 


\section{METHODOLOGY}

The pairs on infrared sensors are spread across the railway tracks at some distance from the barriers. These sensors are directly connected to the Renesas microcontroller. They sense a train when there is a discontinuation in the receiving infrared sensor. According to the sequence of detection in the two sensors, the direction of the train according to the algorithm given in proposed system is concluded. This knowledge of direction can be used to detect any possibility of train collision. It is also used to decide whether to close or open the barrier. Figure 4 shows the flow chart of the proposed system.

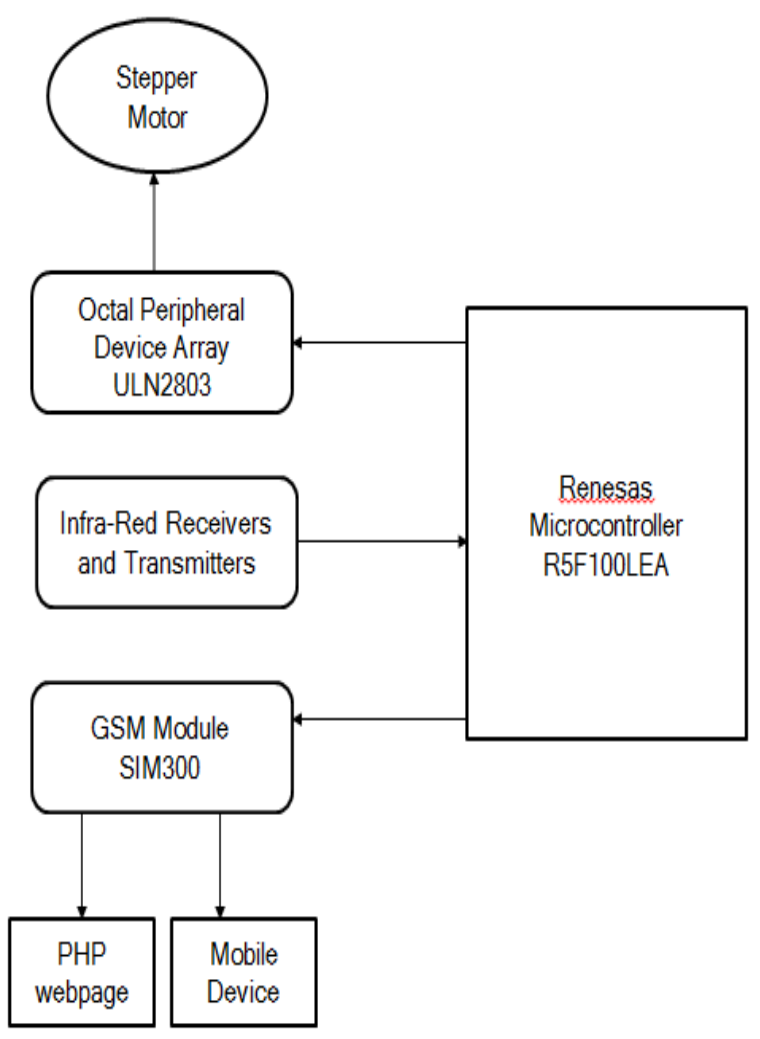

Fig. 4: Flow chart of the system

If the sensor near the barrier senses the train, the barrier is opened or closed. If there is a possibility of collision, a message is sent to the responsible authorities and a webpage is updated about the position of the train according to the input from the sensors.

\section{RESULTS AND DISCUSSION}

The aforementioned system worked successfully with the programmed logic to close/open the barrier gate and to warn the driver and station master about a possible train collision by sending them an SMS to their mobile numbers.

Figure 5 shows the screenshot of the SMS received on the driver's mobile number in case of a possible collision.

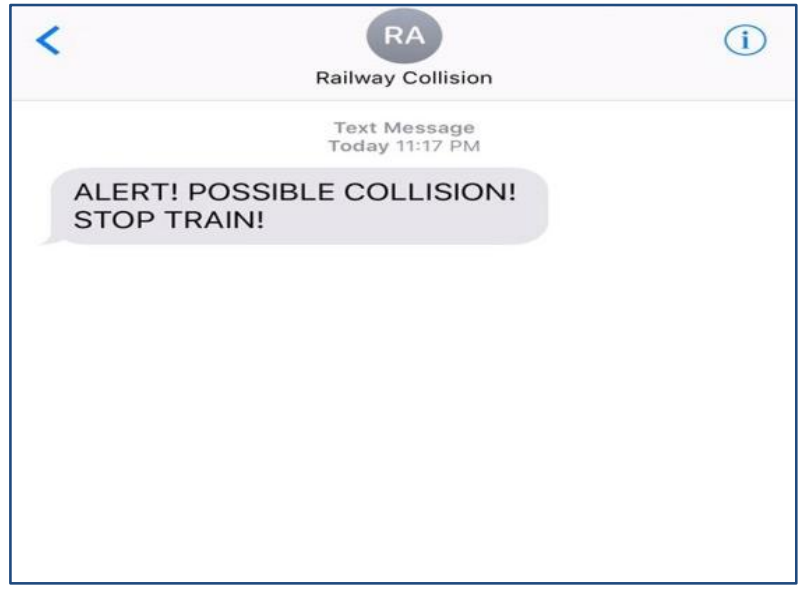

Fig. 5: Screenshot of Collision SMS

It also immediately updates the PHP webpage about the current location of the train according to the sensor location using the GSM module which helps it to connect to the internet and hence update the webpage dynamically. Figure 6 shows the snapshot of the PHP webpage used for showing the current train location.

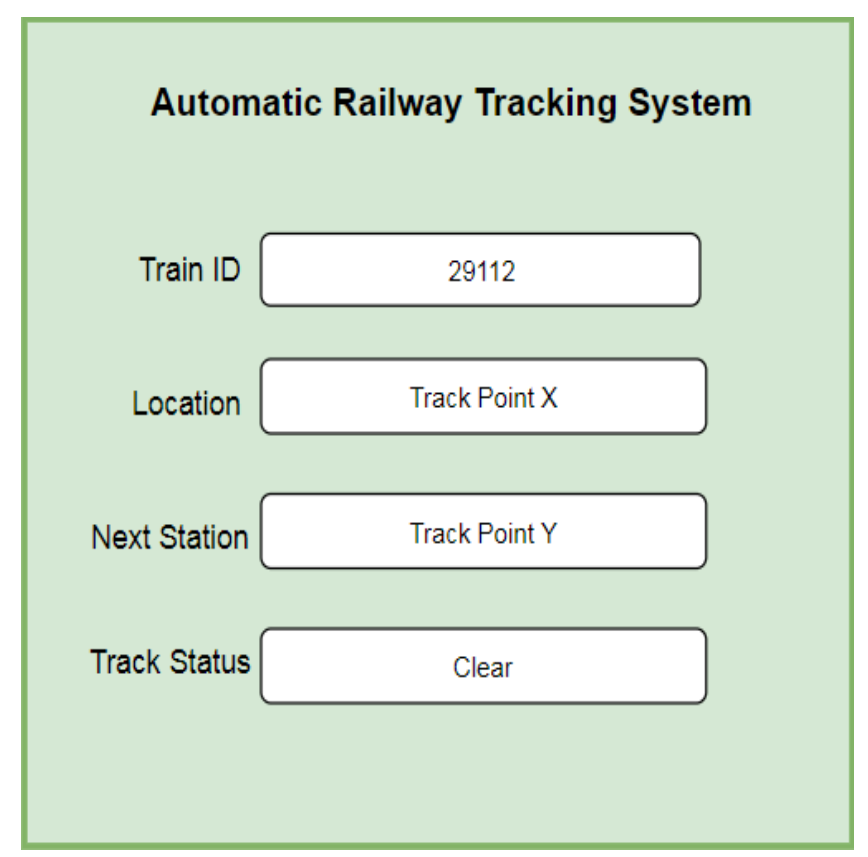

Fig. 6: Snapshot of PHP webpage

\section{CONCLUSION}

In this work, we have studied the existing railway systems, their benefits and drawbacks to create an improved system that can help in decreasing the number of accidents occurring due to human negligence and failure. The proposed model aims to make railways a more reliable source of transport by replacing existing manual systems with automatic barrier control systems. This prevents accidents occurred near level crossings caused by human errors. In addition, it provides precise train information thereby reducing the wait time for road passengers. The features include train collision detection which notifies train drivers and the nearest station about the presence of another train on track which may cause collision. This not only helps in avoiding an accident but can also help in providing faster assistance. Real time train movement detection using IOT makes it easier for passengers to track their train. Also, it ensures railway stations are notified timely 
so that there is no wait time for track clearance thereby delay before train enters the platform is avoided. With collaboration efforts from railway staff and government, contribution of technology in functioning of railways can be increased so that maximum security can be provided to passengers.

\subsection{Further Work}

To further improve the proposed system, RFID sensors and tags can be used instead of IR sensors as they are a better option for saving more details like train number which can be used for various other information to be displayed on the webpage. The current project doesn't uses RFID sensor because of the small scale of the demonstration project. The RFID tags can also be used for detecting possible train collision similar to IR sensors if they are used in pairs of two by checking the timestamps from the two sensors. For further improvement, motion sensors can be deployed at the railway crossing area and alert the driver if there is someone stuck between the barriers so that he can stop the train in time.

\section{ACKNOWLEDGEMENT}

We would like to thank our guide Professor Anusooya G for her valuable suggestions and support throughout this project and the following research paper. We would also like to thank VIT University's Computer Science Department for giving us an opportunity to go forward with this idea and provide us with the resources which led to the successful completion of the project.

We also convey our sincere gratitude to the authors and publications that provided relevant research material for our reference in improving and modelling this paper.

\section{REFERENCES}

[1] https://factly.in/indian-railway-accidents-statisticsreview-last-5-years/

[2] K. Ajith Theja, Dr. M. Kumaresan, Dr. K. Senthil Kumar, Automated Unmanned Railway Level Crossing System Using WSN, International Journal of Innovative Research in Computer and Communication Engineering, Vol. 3, November 2015.
[3] Sayali R., Ruchira J., Rashika K. Tandel and Snehal D., Intelligent Railway Crossing Gate Control with High Speed Anti-Collision Alerting System, National Conference of Role of Engineers in Nation Building, 2015.

[4] Any M. Kottalil, Abhijith S., Ajmal M. M., Abhilash L. J., Ajith Babu, Automatic Railway Gate Control System, International Journal of Advance Research in Electrical Electronics and Instrumentation Engineering, Vol.3, February 2014.

[5] Sheikh Shanawaz Mostafa, Md. Mahbub Hossian, Khondker Jahid Reza, Gazi Maniur Rashid A Radio Based Intelligent Railway Grade Crossing System to Avoid Collision, International Journal of Computer Science Issues, Vol.2, November 2010.

[6] Prashantha B.Y. and Harisha S. Smart, Railway Crossing Embedded with Automated Platform Bridges, International Journal of Research in Engineering and Technology, 2015.

[7] Srishti Rawal, Internet Of Things (IOT) based Smart Irrigation System, International Journal of Computer Applications, Vol.2, February 2017.

[8] Nisha S. Punekar, Archana A. Raut, Improving Railway Safety with Obstacle Detection and Tracking System using GPS-GSM Model, International Journal of Scientific and Engineering Research, Vol.4, August 2013.

[9] D. Karthiga Devi, M Jeya Sudha, K.Kirthiga, N.Shanmuga Sundari, Automatic Railway Track Obstacle Detection System International Journal of Informative \& Futuristic Research, Vol.2, March 2016.

[10] Rohan D. Dudam, Mandar C. Koshti, Nirmal Kumar, IEEE Automatic Railway Gate Control System, https://www.academia.edu/5914238/IEEE_Automatic_R ailway_Gate_Control_System

[11] http://www.electronicshub.org/automatic-railway-gatecontroller/ 